\title{
As reviravoltas da história e da ficção no diário do Conselheiro Aires
}

Matildes Demetrio dos Santos

Recebido em 21 mai 2012 - Aprovado 26 set 2012

\begin{abstract}
Resumo
O último romance de Machado de Assis, Memorial de Aires (1908), transita entre a história e a ficção. Este trabalho objetiva analisar a estrutura da obra, revelando seus elementos ficcionais, expondo o talento do autor na construção de uma narrativa sob a forma de um diário imaginário.
\end{abstract}

Palavras-chave: ficção e história; diário; Machado de Assis 


\section{O Diário e a História}

Não é significativo que Machado de Assis, um escritor que sempre investiu contra as facilidades da escrita, tenha decidido escrever o seu último livro, Memorial de Aires, sob a forma de um diário? Seria o diário uma proteção contra a vaidade do escritor genial? Uma defesa aparentemente inofensiva contra o perigo de uma escrita cada vez mais exigente? Se assim é, o diário com seu traçado livre e aparente simplicidade formal fornece a ilusão de escrever longe dos olhares indiscretos. Preso ao cotidiano, o diarista só precisa anotar a data acima do texto a ser escrito e, este gesto tão simples, mas característico do diário, já garante a autenticidade do momento e a oportunidade de arquivar sua história pessoal, deixando rastros para dias futuros.

Desde o final do século XVIII, o diário é utilizado pelos amantes da escrita como um instrumento de ação e de sobrevivência. Na página em branco, o solitário se revela e semeia questões que, depois, poderão ser repensadas. É uma escrita receptiva aos movimentos introspectivos da alma, criando espaços para confissões e questionamentos. Inserida no tempo pode ser uma forma de resistência à doença, à velhice ou à prisão, um meio de vencer a solidão e o sofrimento. Diferente da autobiografia ou da memória, que trabalham com um passado conhecido, o diário capta o que foi escrito num certo momento, numa forma livre, sem grandes preocupações estéticas.

O Memorial de Aires, publicado em 1908, abre-se a estas dimensões. $\mathrm{O}$ gênero proporciona ao autor a liberdade de criação e, na sucessão dos dias, torna-se possível discorrer sobre o tempo que passa à sua volta. Para Philippe Lejeune, (2008, p. 265), o diarista pode encontrar nas suas anotações, "a doçura de existir em palavras e a esperança de deixar vestígios". Talvez seja essa a intenção de Machado de Assis no Memorial de Aires pois, na sua forma híbrida e elástica, o diário atende ao interesse do historiador e do ficcionista. Por um lado, elege os anos de 1888 e 1889, datas que figuram nos livros de História do Brasil, marcando a Abolição da Escravatura e a Proclamação da República, por outro, como a forma é livre, ele pode escolher o estilo, inserir elementos ficcionais, valorizar a linguagem literária.

Como romancista, Machado de Assis sempre demonstrou ter "certo sentimento íntimo que o torn[ou] homem de seu tempo e do seu país" (OC, III, p. 804) e, no Memorial, ele confirma a sua contemporaneidade ao utilizar o diário como memória viva dos conflitos, que ocorreram no Brasil do final do século XIX e pode atuar como um observador privilegiado, atento às reações dos cafeicultores do vale do Paraíba que, sem o apoio da monarquia, foram forçados a aderir à causa abolicionista e libertar, sem indenização, os seus escravos. O livro sublinha esse passado, dando-lhe uma "identidade narrativa" (LEJEUNE, 2008, p. 262), o que tornará 
essa história memoriável, fazendo com que o conteúdo histórico encontre forma no romance, dramatizado por personagens pertencentes à classe alta brasileira.

Como é de praxe na obra machadiana, o elo com a nação está rodeado de questionamentos e, no Memorial, Machado não poderia ser mais explícito: não há transformação, não há solidariedade no Brasil pós-escravidão. Fidélia e Tristão, moços inteligentes e bem postos na vida, casam-se e vão viver na Europa, levando o futuro na bagagem. Na cena final do livro, transição para a República, Aires e seu voyeurismo saem de cena, deixando os velhos, os Aguilar, com seus suspiros feitos de aceitação; inércia e saudade. É angustiante o ceticismo do escritor em relação a um Brasil fraturado e corrompido pela escravidão e sua herança.

O Memorial de Aires começa no Rio de Janeiro, do início de 1888, com a voz de um vendedor de vassouras e espanadores: "Vai vassouras! Vai espanadores!" O pregão é uma alusão irônica à queda iminente dos barões do café ao mesmo tempo em que faz ecoar o clima confuso e caótico, que se vivia nas ruas a favor da causa abolicionista. Em uma época em que não havia um vínculo adequado entre a classe senhorial e o restante da população, o fervilhamento das ruas testemunhava a crença de que a luta pela extinção do escravismo criava oportunidades de mudança para muitos escravos que já abandonavam as fazendas e se empregavam por salário em estabelecimentos comerciais. Sem alternativa, muitos proprietários foram obrigados a aceitar a mão de obra disponível para não interromperem o trabalho nas fazendas. E o diário capta essa movimentação, construindo-se na linha sinuosa entre as ações da vida privada dos salões residenciais e a movimentação abolicionista.

No século XIX, o "privado" era, principalmente, constituído por uma aristocracia urbana e rural, um grupo social definido pela família e pelos amigos dos ricos proprietários de terra, donos de fazendas de café no Vale do Paraíba, funcionários públicos de alto escalão, desembargadores, banqueiros. Herdeiros do passado colonial, ostentando títulos de nobreza, essa classe concentrava poder e riqueza, gozava de enorme prestígio junto às instituições monárquico-constitucionais, interferindo ou atuando diretamente na política do país. Sutilmente, o discurso do diário centraliza seu olhar nas reações dessa elite contrária ou simpatizante ao abolicionismo no trânsito para o futuro republicano, apoiando-se na técnica progressiva da escrita rotineira que armazena os acontecimentos do dia, prolonga o tempo histórico, medindo as datas, colaborando com a reflexão histórica. O Memorial flagra a agonia dos fazendeiros, que não se conformavam com a perda de domínio e defendiam as prerrogativas de seu poder sobre os escravos, preferindo emancipá-los coletivamente a se submeterem às decisões governamentais. Atraído pelas reações dos protagonistas, o diarista informa que, no dia 10 de abril de 1888, o Barão 
deSanta-Pia, cafeicultor e chefe político na Paraíba do Sul, decidiu alforriar imediatamente todos os seus escravos. Na interpretação do desembargador Campos, irmão de Pia, tratava-se de uma retaliação à idéia atribuída ao governo de decretar a abolição: “O ato que ele resolveu fazer exprime apenas a sinceridade das suas convicções e o seu gênio violento. Ele é capaz de propor a todos os senhores a alforria dos escravos já, e no dia seguinte propor a queda do governo que tentar fazê-lo por lei". Junto a esses motivos, o fazendeiro tinha a certeza de que a maioria dos seus escravos, por não terem para onde ir, ficaria na fazenda ganhando o salário que ele lhes oferecesse, - "pelo gosto de morrer onde nasceram" (O C, I, p. 1.116).

A política de dominação do mais forte sobrevivia também no seio da família. No dia 14 de janeiro, o escritor anota mais uma particularidade da biografia desse senhor de escravos. Ele, apesar de enfermo, estava de relações cortadas com Fidélia, sua única filha, porque ela se apaixonou, se rebelou e resolveu casar com Noronha, filho de um de seus inimigos políticos. Como consequência, a moça teve negado o direito de entrar na casa paterna e foi condenada a viver longe dos entes queridos, mesmo depois de ter ficado viúva.

Com tempo para refletir sobre o drama entre pai e filha, o diarista relembra a tragédia de Romeu e Julieta, seres de ficção que se amaram, apesar da inimizade entre as famílias e sucumbiram face à intolerância e à brutalidade. Tendo em vista os cânones do gênero trágico, a morte dos amantes de Shakespeare está intimamente relacionada ao desempenho de um modelo retórico de sentimentos levados às últimas consequências. No entanto, ao articular essas paixões a acontecimentos da vida doméstica no Brasil, a voz que se manifesta em primeira pessoa torna explícito o argumento de que, diferente da ficção, em qualquer município de norte a sul do país, os ódios familiares semeiam desgraças que atravessam gerações, deixando atrás de si um rastro de destruição e morte. No argumento de Aires: "Aqui a oposição dos rebentos continua a das raízes, e cada árvore brota de si mesma, sem lançar galhos à outra, e esterilizando-lhe o terreno, se pode" (O C, I, p. 1.100).

É, sem dúvida, um depoimento elucidativo quanto à realidade do mundo patriarcal brasileiro, com seus costumes e preconceitos. A intuição aguda do memorialista persiste na trilha interpretativa, firme no interesse de acompanhar o destino dos ex-cativos de Santa-Pia que, com a morte dos pais, tornam-se responsáveis pela própria sobrevivência. De modo sintético, sem abdicar da questão, o diarista comenta que o problema de saúde do barão se agravou e ele veio a falecer. Como de praxe, a viúva Noronha tomou posse de sua herança e o texto escrito põe em cena o seu desempenho diante dos acontecimentos centrais de sua época. 
Aires, pressentindo mudanças na condução da fazenda, não vacila e, na página de 30 de junho de 1888, anota que, para a moça que vivia na cidade, foi comovente, depois de tantos anos, poder matar as saudades da casa em que nasceu e reencontrar "mucamas e moleques deixados pequenos e encontrados crescidos, livres com a mesma afeição de escravos". Por trás do desempenho sentimental, dois dias depois, o diarista acentua, entre as linhas de 2 de julho que, apesar de ter bons sentimentos e demonstrar espírito de liderança, Fidélia não se ajustava à linha contínua e descendente do pai: "parece-lhe que a lavoura decai, e não se sente com forças para sustê-la. Daí a idéia de vender tudo". Para concluir que, na verdade, Fidélia não se reconhecia na história de sua família e, para o memorialista, não foi difícil perceber no projeto de Fidélia o espelhamento de uma ideologia conformista, ignorante do sentido das contradições sociais baseadas no paternalismo. Na tensão entre a referência e a ironia, ele anota no segundo parágrafo da página de 10 de agosto, o que ficou estabelecido:

Fidélia chegou da Paraíba do Sul no dia 15 ou 16. Parece que os libertos vão ficar tristes; sabendo que ela transfere a fazenda pediram-lhe que não, que a não vendesse, ou que os trouxesse a todos consigo. Eis aí o que é ser formosa e ter o dom de cativar. Desse outro cativeiro não há cartas nem leis que libertem; são vínculos perpétuos e divinos. Tinha graça vê-la chegar à Corte com os libertos atrás de si, e para que, e como sustentá-los? Custou-lhe muito fazer entender aos pobres sujeitos que eles precisam trabalhar, e aqui não teria como nem onde os empregar logo. Prometeulhes, sim, não os esquecer, e, caso não torne à roça, recomendá-los ao novo dono da propriedade (O C, I, p. 1.138).

Como num piscar de olhos, Santa-Pia foi vendida. O interesse pelo desenrolar da situação, leva o diarista a detectar um sério problema na resolução de Fidélia ao passar adiante a fazenda e seus dependentes. Fingindo familiaridade, sem ultrapassar as regras do decoro, ele pergunta se ela não sentiria saudades da casa em que nasceu e se criou. Rapidamente, a viúva respondeu que sim, "mas já não terá gosto em lá viver" e logo adiantou: "- Aquilo agora é para mãos de homem". Os presentes ouviram estas palavras com vivo prazer e o assunto morreu ali, conforme foi registrado no dia 10 de outubro de 1888. Fecha-se o círculo em relação à sorte dos ex-cativos. O diarista não ousa acrescentar nada, apenas autentica as versões que estão à sua volta, respeitando o movimento de progressão no espaço da sua realização, embora o eu sempre tenha algo a comunicar sobre si mesmo e crie oportunidades para levar adiante a sua reflexão sobre a classe média brasileira face às reviravoltas históricas e políticas nos últimos anos do século XIX. Nesse ponto, o diário é o lugar privilegiado para a invenção de assuntos, espaço propício para geniais habilidades literárias. 


\section{O Diário e a Ficção}

O Memorial de Aires vale pelos capítulos selecionados da História do Brasil, pelo rigor da intriga, pela verdade de seus personagens e pela coragem do autor em "se deixar levar" ao utilizar no seu livro, um gênero passageiro como o diário.

E, no entanto, a Advertência já responde a motivações variadas. Nela, não surge o nome de Machado de Assis, mas o do editor M DE A., um pseudônimo, que tem a preocupação de informar que o diário pertence ao Conselheiro Aires, um diplomata aposentado que, nas horas de solidão, tinha o hábito de guardar por escrito as suas observações, reflexões, críticas e anedotas, tendo para isso uma série de cadernos a que batizou de memorial. O editor, quando resolveu publicar os cadernos referentes a 1888-1889, teve o cuidado de conservar do "original, só o que liga ao mesmo assunto", convicto de que, "apesar da forma de diário que tem" podia despertar o interesse de quem o lesse.

Correção ou interesse por uma escrita fragmentada, mas existencial, cheia de vida e vitalidade? Os desvios filtram a vertente documental e revela a intromissão de um primeiro leitor que interfere nos manuscritos do livro. Por seu lado, Machado de Assis, instância criadora do personagem e do editor, também se insinua, apresentando-se como co-autor do memorial, ao estabelecer uma ligação do novo livro com um romance seu, o de 1904: "Quem me leu Esaú e Jacó talvez reconheça estas palavras do prefácio" (O C, I, p. 1.096).

Na sequência, fica registrado o empenho do autor em justificar sua restrição à história e afirmar o compromisso de que a obra literária pode servir à análise da sociedade, porém sua intenção é outra. Aparecer ao lado de entidades ficcionais é a prova de que há um desejo irreprimível de liberdade, que advoga a onipresença da ficcionalidade. Se a escrita da História necessita de uma assinatura, que autentique o conteúdo afirmado; a perspectiva de distanciamento do verdadeiro autor redefine esse sentido, ao mesmo tempo em que problematiza a oposição simples e binária, entre res fictae e res factae, ao desenvolver relações complexas entre a história e a literatura no momento em que incorpora o "como

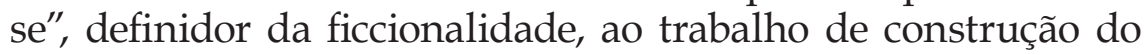
presente histórico.

Esse processo é estudado por Wolfgang Iser em $O$ fictício e $o$ imaginário (1996, p. 16-23), ao explicar que tanto a narrativa do historiador quanto a do ficcionista empregam os dois procedimentos do ato de fingir, isto é, os atos de seleção de elementos do real e de combinação desses elementos em um relato determinado. Portanto, o desnudamento da ficcionalidade proposto por Machado de Assis no Memorial expressa um convite à recepção do livro, definindo um ato e um modo específicos de leitura. A hipótese é a de que se trata da narrativa íntima de Aires que, para fugir à vertigi- 
nosa passagem do tempo, reconstrói o que pode do momento que lhe resta para viver. Sendo assim, cabe a essa figura ordenar a narração da "própria" vida, submisso a regras semânticas e pragmáticas que evidenciam a sua situação atual e esclarecem o motivo do diário: Dia 12 de novembro de 1888, "a aposentação me restituiu a mim mesmo; mas lá vem dia em que, não saindo de casa e cansado de ler, sou obrigado a falar, e, não podendo falar só, escrevo" (O C, I, p. 1. 168).

No entanto, esse narrador, tão descompromissado com a escrita, oscila entre o escritor comum, que se apropria do prosaico e o genial, que desenvolve um estilo literário claro, ligeiramente irônico, com associações interessantes, erudito e filosófico. Aires busca no papel uma reação ao tempo que passa, ligado a uma verdade íntima e secreta, como confessa em 9 de janeiro de 1888: "Não morro de saudades por nada. Aqui estou, aqui vivo, aqui morrerei".

Qualquer que tenha sido a sua vida é no diário que ele se abre para todos os lados, pronto a romper o silêncio e dar testemunho de suas necessidades. Como o comentário sobre os fatos ocupam um lugar de destaque nos seus cadernos, Aires tem o hábito de datar com relativa precisão cronológica o tempo transcorrido, guardando tudo para si, preso ao calendário que, segundo Maurice Blanchot (2005, p. 270), é do diarista, o "demônio, o inspirador, o compositor, o provocador e o vigilante". O tempo socializado no calendário, entretanto, desdobra-se no ato da enunciação como manifestação individual. Ao escrever, o 'agora' torna-se atual e refratário a toda e qualquer história e o narrador fica livre para operar simultaneamente como aquele que testemunha e documenta a história de sua época.

Instigado pelo calendário, o narrador noticia o 13 de maio de 1888, dia da Abolição da Escravatura, detendo-se na observação do comportamento da sociedade fluminense no espaço público. Primeiramente, o assunto gira em torno do episódio, que viveu na rua do Ouvidor, centro do Rio de Janeiro, "onde a agitação era grande e a alegria geral". Um conhecido, vendo-o ali, convidou-o a participar do cortejo organizado para ovacionar a Princesa Isabel. Atordoado com o barulho, quase aceitou o convite, porém logo se recompôs, e ficou onde estava. Depois, com calma, repensando a decisão de não ter ido aclamar a Regente, concluiu envergonhado: "Se eu lá fosse provavelmente faria o mesmo e ainda agora não me teria entendido... Não, não faria nada; meteria a cara entre os joelhos" (O C, I, p. 1.118).

A confissão inesperada realça o comportamento deslocado de Aires, que parece não ter tido uma posição política estrategicamente definida, através da qual poderia ter atuado contra as tiranias do sistema. O desconforto fica por conta do subentendido de que as ações diplomáticas não se definem às claras, ao contrário; na diplomacia, aprende-se a atuar em várias frentes de batalha, 
movido por interesses de naturezas diversas e, a cada disputa, vira-se o jogo para não perder o poder.

$\mathrm{Na}$ consciência dos políticos, do clero católico, dos donos de escravos, era preciso conservar a escravidão para que a estabilidade e a unidade do país não fossem ameaçadas. De acordo com essa hipótese, houve uma espécie de pacto da classe dominante no sentido de evitar guerras e revoltas separatistas. Esse profundo enraizamento ajuda a explicar por que o movimento abolicionista nas ruas não pareceu tocar a sensibilidade da classe alta brasileira. É Joaquim Nabuco quem argumenta: "a relação senhor-escravo transportava-se para dentro da própria prática política, contaminando a cidadania com os germes do autoritarismo e do paternalismo" (CHALHOUB, 2012, p. 26).

$\mathrm{O}$ argumento de Nabuco pode ser creditado a Aires ao identificar no caráter de seus amigos o comportamento que ele próprio herdara: "Não há alegria pública que valha uma boa alegria particular". Com essas palavras escritas nos primeiros minutos do dia 14 de maio, ele conta a noite passada na casa dos Aguiar. Logo que chegou, sentiu-se contagiado pela alegria dos donos da casa, pensando que o fato se devia ao número de pessoas reunidas para comemorar o grande acontecimento do dia. Para sua surpresa, a razão era a carta de Tristão, afilhado do casal, avisando de sua chegada ao Brasil. A solução foi esconder o mal-entendido e disfarçar com o melhor dos sorrisos, limitando-se a participar da alegria geral. Comentando o episódio, ele entende que o grupo a que pertence vive mergulhado em si mesmo, comportando-se como se fosse estranho ao comportamento de todos os demais. No meio deles, guarda o que pensa e o que deixou de pensar: "Compreendi. Eis aí como, em meio do prazer geral, pode aparecer um particular, e dominá-lo. Não me enfadei com isso; ao contrário, achei-lhes razão, e gostei de os ver sinceros" $(O$ C, I, p. 1.119). Nos dois momentos, a atitude do Conselheiro reforça os rituais de silêncio e reverência dos dependentes da classe dominante. Na rua, no calor da hora, evita a exposição pública e refere-se à inutilidade das manifestações ruidosas. Nas relações sociais, nas quais reina a vontade senhorial, esconde seus objetivos e faz exatamente aquilo que se espera dele.

Tristão é também um personagem escolhido com cuidado para compor o painel dos brasileiros, que mantém relações conflituosas com a sua pátria. Apesar de brasileiro, foi criado em Portugal e não tem pretensão alguma de fixar raízes na terra natal. De passagem pelo Rio de Janeiro, o jovem elegante, formado em medicina e muito viajado, tem planos de voltar para Lisboa e ingressar na política. Nele, Aires não reconhece um marco de ruptura histórica, assinalando a esperança de um Brasil mais saudável. E quando ele retorna a Portugal, levando na bagagem a rica Fidélia, pinta a certeza de que se perpetua a antiga posição de domínio e a sobrevida da política de dominação. 
Aires circula livremente e observa todos os estados da sociedade. Contudo como a sua perspectiva é estreita e dependente da dimensão temporal do presente, todas as suas insinuações são dirigidas a si mesmo e o seu olhar não vai muito longe, permanecendo nos limites da observação externa. Por mais que olhe o seu modelo, ele não alcança o "seu interior" e precisa contentar-se com o verossímil. O retrato de Tristão, dos demais personagens da trama, as peripécias do amor, os fatos ocasionais, tudo é construído aos poucos, vagarosamente, dissimulando os recursos ficcionais, fiel à técnica de uma escrita que ignora a onisciência e precisa esperar pelo dia seguinte. Daí a urgência, por exigência do comunicado: "Venho da gente Aguiar, e não me quero deitar sem escrever primeiro o que lá se passou" $(O$ C, I, p. 1.149).

$O$ texto encabeçado com a data de 18 de setembro é longo e descontínuo. Nele, o assunto gira em torno das qualidades de Tristão e o seu regresso a Lisboa. D. Carmo e Aguiar não poupam elogios ao afilhado. A opinião contraria o diplomata. Pensa que Fidélia, na visão dos pais adotados, era igualmente perfeita e eles poderiam estar enganados. No entanto, a suspeita de Aires é pessoal e ele não encontra motivo para contrariar os veredictos. Recolhido em si, o texto se arrasta, meio enfadonho. Procura brincar com os sentimentos dos velhos, escrevendo frases rimadas, do tipo: "felicidade rima com eternidade, e estes eram felizes" ou, repetindo gastas filosofias de almanaque,: "Respondi que trazia a minha velhice para somar as duas e formar uma só e verde mocidade, das que já não há mais na terra". A página dá uma boa ideia do fervilhamento dos desconfortos que o papel recolhia. De repente, como diante do espelho, o eu vê a sua imagem: "e eu tive de ouvir com aquela complacência, que é uma qualidade minha, e não das novas. Quase que a trouxe da escola, se não do berço". Os seus olhos o veem como um ser cordial, amigo dos homens. Na sua origem, desde o nascimento, existiu apenas benevolência e sentimentos ternos. Escuta a voz da mãe dizendo que ele fazia cara feia, mas não chorava quando tinha fome. Na escola, nunca brigou com ninguém, foi sempre um conciliador, sempre soube fazer de sua "alma um compasso, que abria a ponta aos dois extremos". Voltando a si, reconhece feliz que a vida não o transformou: "Não quero elogiar-me... Onde estava eu? Ah! No ponto em que os dois velhos diziam qualidades do moço (O C, I, p. 1.151).

No entanto, quem lê o diário pode acompanhar de perto essa autoanálise e perceber que Aires escolheu essa forma de agir para escapar, sem aborrecimentos e contrariedades, às pressões sociais. O narrador recusa a via do confronto, preferindo calar a agir. A manutenção do diário o ajuda a recuperar as energias perdidas nos silêncios acumulado. Viúvo, com 63 anos, com poucos amigos, o Conselheiro procurava no trato social, relativizar os atos humanos para evitar conflitos e inimizades. Como afirma Lejeune (2008, p. 263), o ato de escrever forçava-o "a formular os 
desafios e os argumentos, deixando vestígios que poderão ser repensados". Ora, o enfado, as hesitações, a autoestima elevada indiciam o ciúme do velho diplomata incomodado com os elogios endereçados a Tristão; todavia, o diário alimentava a sua autoestima e o ajudava a manter a dignidade.

O esforço, muitas vezes, lhe permitia medir as próprias convicções e dar vazão à sabedoria de cidadão do mundo, dono de um vasto conhecimento. As leituras de Aires abrangem os campos da política, da filosofia, da religião e da literatura. Um dos exercícios de sua prosa é comentar e plagiar seus autores preferidos. Com saborosa inteligência, ele incorporava a leitura dos clássicos à escrita do presente. Esse método atualiza e vivifica a tradição literária. Com autoridade intelectual, o narrador transformava sua escrita em co-produto dessa inestimável tradição, apropriando-se de textos alheios, tirando partido deles, enriquecendo-lhe o sentido. Por exemplo, Aires costumava citar o verso de Shelley, I can give not what man call love, (Não posso dar o que os homens chamam de amor), como desculpa para não se insinuar para Fidélia como sugeriu sua irmã. Em outra ocasião, tocado pela beleza da moça repetia o mesmo verso, acrescido da frase "e é pena". Ao conhecer melhor a moça, Aires não se conformava em renunciar ao amor por causa da idade avançada. Tempo depois, nas linhas de 17 de agosto de 1888, mentia sobre a pureza de seus sentimentos: "Os olhos que pus na viúva Noronha foram de admiração pura, sem a mínima intenção de outra espécie, como nos primeiros dias desse ano" (O C, I, p. 1.139). Quase um ano depois, 18 de julho de 1889, com o eco da voz de Fidélia, já casada e de mudança para Lisboa, Aires se alvoroça e, com ardor juvenil, exclamava: "ela desfeita em graça, eu desmentindo Shelley com todas as forças sexagenárias restantes. Ah! Basta!"

No diário, Aires é capaz de oferecer de si mesmo uma imagem mais válida, revelando pequenos gestos ou qualquer outro sentimento internalizado pela emoção ou pela imaginação. A solidão, o silêncio, o acaso, um encontro, um sonho, uma lembrança, um rosto deixam sua marca no diarista, impondo um novo caminho à narrativa. Quando vinha o cansaço, às vezes sacrificava a lembrança, mas sentia-se compensado ao deixar que a impressão passasse para ficar apenas com o que valia a pena guardar, pois a voz que fala no diário é exigente, embora disfarce as exigências literárias, adotando a pose de quem não se reconhece como autor. Nos meandros da trama, ele deixa entrever o esforço para colocar os assuntos na sua forma própria. É sintomática a ligação com "o amigo papel". Ali onde escreve, dirige-se a "ele", tratando-o com familiaridade, incluindo-o na fabulação com o estatuto de "outro autor": "Papel, amigo papel, não recolhas tudo o que escrever esta pena vadia. Querendo servir-me, acabarás desservindo-me". Redundantes, os lembretes e as advertências estão a serviço do estilo: “Não papel. Quando 
sentires que insisto nessa nota, esquiva-te da minha mesa, e foge" (O C, I, p. 1.115-1.116).

Aires odeia a dispersão e desafia essa escrita suscetível às emoções do cotidiano, pronta a receber as mudanças de humor. Para ele, seria mais fácil escrever um romance, com a liberdade de inventar à vontade. No dia 24 de agosto, ele pega da pena para explicar "a sombra da sombra de uma lágrima", que ele acredita ter visto, dois dias antes, nos olhos de Fidélia, quando se referiu à dissidência do pai e do marido. Mas como narra na forma que lhe convém? A impressão passageira em vez de ser explicada, é substituída por considerações, carregadas de preconceito. Inicia dizendo que as lágrimas, mesmo nos olhos das mulheres, são confissões de fraqueza e ele tem tédio pelos fracos. Repensa, e volta a afirmar que as mulheres são menos fracas, ou mais pacientes para suportar as dores e adversidades da vida. As idéias vão ocorrendo e, quando nota: "Aí está; tinha resolvido não escrever mais, e lá vai uma página com a sombra da sombra de um assunto" (O C, I, p. 1.141).

No final dessa página, desvenda-se algo bastante diferente da vontade obsessiva de escrever sobre qualquer assunto: "Se eu não tivesse os olhos adoentados dava-me a compor outro Eclesiastes, à moderna". Mesmo acreditando que tudo é fugaz, vago e contraditório nesse mundo, Aires forma, no memorial, um perfil de escritor. Ele começa a escrever para enfrentar a aposentadoria, mas a prática acabou sendo a oportunidade para criar um enredo original, construído com a falsa feição de um texto se fazendo. E, como se trata da atividade de um velho, às vezes, há uma confusão de datas, um esquecimento, um pouco de preguiça. Aires reconhece, procura defender-se, como? Nada detém o tempo e seus estragos: No dia 21 de agosto, 5 horas da tarde, escreveu desanimado: "Não quero acabar o dia de hoje sem escrever que tenho os olhos cansados, acaso doentes, e não sei se continuarei este diário de fatos, impressões e idéias. Talvez seja melhor parar" (O C, I, p. 1.141).

O diário de Aires traduz as mutações da velhice e para quem "tinha o gosto de ter a pena na mão" era penoso interromper o escrito por causa de um reumatismo ou por necessidade de repouso. Acontece que a doença não afasta o diarista da escrita e ele não se mostra disposto a largar o diário. Tal disposição traz à tona a afirmação de Lejeune (2008, p. 270): “o diário é vivido como escrita sem fim". De fato, entre agosto e setembro de 1889, sem data precisa, o conselheiro interrompe a escrita do seu memorial, deixando, todavia, a página aberta, sujeita a retomada ou, talvez, a reinterpretações futuras...

\section{Ainda o diário...}

No término do percurso cumpre responder às interrogações do início. Em primeiro lugar, a utilização do diário no traçado de o 
Memorial de Aires é uma estratégia para disfarçar a distância entrea ficção e a história. No diário, o autor comunica-se silenciosamente com o leitor sobre qualquer assunto, sem riscos, numa relação individual e íntima. Segundo, o diário é uma ficção dissimulada e pretensiosa. Sua narrativa segue, de maneira convencional, o calendário, mas se inscreve no campo do conhecimento histórico e transmite as singularidades do eu que conta a história dos seus dias. O autor de um diário coloca-se na posição intermediária entre a ficção e a história. Como historiador, recorta, seleciona e organiza cronologicamente o material recolhido e como ficcionista, afeito à imaginação e à fabulação, produz unidades de sentido, ligando o material histórico a personagens inventados de modo a formar o arcabouço completo da obra. Desse modo, o espaço literário do romance pode ser utilizado para desenvolver os recursos, que caracterizam a especificidade narrativa do estilo de um autor. No caso de o Memorial de Aires: um narrador comunicativo, irônico e inteligente, ficcionaliza notícias históricas, filosofa, pratica a metalinguagem. Sendo assim, esse diário imaginário articula fragmentos e rastros da natureza jornalística de um Machado de Assis, que emerge na irrealidade de sua ficção para testemunhar o presente de um tempo.

\begin{abstract}
Last novel by Machado de Assis (1908), Memorial de Aires, moves between History and Literature. This study intends to get into the work structure, revealing its fictional elements and show the literary talent of the author in the construction of the narrative under the shape of an imaginary diary.
\end{abstract}

Keywords: ficction and history; diary; Machado de Assis

\title{
REFERÊNCIAS
}

ASSIS, Machado de. Obras completas. Rio de Janeiro: Editora Nova Aguilar, 1989, $3 \mathrm{v}$.

BLANCHOT, Maurice. O diário íntimo e a narrativa. In:

O livro por vir. Trad. Leyla Perrone-Moisés. São Paulo: Martins Fontes, 2005.

CHALHOUB, Sidney. População e sociedade. In: CARVALHO, José Murilo de (Org.). A construção nacional 1830-1889. Rio de Janeiro: Objetiva, 2012, v. 2.

ISER, Wolfgang. O fictício e o imaginário: perspectivas de uma antropologia literária. Trad. Johannes Kretschmer. Rio de Janeiro: EdUERJ, 1996 (Especialmente capítulo I, p. 16-23). 
LEJEUNE, Philippe. O pacto autobiográfico De Rousseau à internet. Trad. Jovita Maria Gerheim Noronha, Maria Inês Coimbra Guedes. Belo Horizonte: Editora UFMG, 2008, p. 257-340.

PEREIRA, Affonso de M., CHALHOUB, Sidney (Org.). A história contada Capítulos de história social da literatura brasileira. Rio de Janeiro: Nova Fronteira, 1998. 